\title{
VEHICLE DATA PROCESSING AND REPORTING SYSTEM FOR SMART CITY BUSES
}

\author{
Enis AYTAR ${ }^{1}$, Serkan MEZARCIÖZ ${ }^{1}$, Murat DEMIRDÜZEN ${ }^{1}$, Mert \\ ÖZKAYNAK ${ }^{1}$, Kadir AYDIN ${ }^{2}$ \\ ${ }^{1}$ Temsa Global San. Ve Tic A.Ş. R\&D Center \\ ${ }^{2}$ University Of Cukurova, Department Of Automotive Engineering
}

\begin{abstract}
In the current study, a data processing and reporting system was established to a smart city bus. With the application of this system, the vehicle had capability of processing, sending and reporting data in the vehicle as requested by the driver, owner and/or fleet management center via internet.
\end{abstract}

Some properties of the system can be summarized as follows; some of the vehicle parameters like instantaneous/average fuel consumption, engine speed, throttle pedal position, vehicle speed, engine coolant temperature, brake lining thickness, fuel level, etc can be limited by the driver, owner or fleet manager. And in the case of exceeding these limits, some warning symbols can be displayed in the touchable driver information display to warn the driver. At the mean time, these data can be saved and monitored online by the fleet management center via internet. By processing these data, performance of drivers of the fleet can also be evaluated.

With the application of this system, vehicle can be diagnosed without any need of special diagnose tool and all error codes for engine, transmission, brake or any other system in the bus can be monitored on fully programmable, touchable driver information display of the bus.

Another advantage of employing this system to the city bus is to see the condition of the vehicle, situation of the systems, error codes and 
special parameters like pressure in the brake lines, throttle pedal position, park brake status just before any accident. And this information can help to find out the cause of the accident.

In the current study, application details, system components and software details of the system were discussed and explained in detail.

Keywords: Data Processing, Vehicle Diagnose, Driver Information Display, Internet of Thing, Smart City bus.

\section{INTRODUCTION}

Information technology (IT) has transformed many industries, from education to health care to government, and is now in the early stages of transforming transportation systems. While many think improving a country's transportation system solely means building new roads or repairing aging infrastructures, the future of transportation lies not only in concrete and steel, but also increasingly in using IT. IT enables elements within the transportation system-vehicles, roads, traffic lights, message signs, etc.- to become intelligent by embedding them with microchips and sensors and empowering them to communicate with each other through wireless technologies. In the leading nations in the world, ITS bring significant improvement in transportation system performance, including reduced congestion and increased safety and traveler convenience [1].

Intelligent Transport Systems (ITS) are advanced applications to collect, storage and process data, information and knowledge aiming at planning, implementing and evaluating integrated initiatives and policies of Smart Mobility. [2].

In the current study, a data processing and reporting system was established to a smart city bus. With the application of this system, the vehicle had capability of processing, sending and reporting data in the vehicle as requested by the driver, municipality, owner and/or fleet management center via internet. 


\section{MATERIAL AND METHOD}

Vehicle data processing and reporting system includes driver information display, telemetry device, $3 \mathrm{G}$ communication, big data infrastructure, web application, application database, smart city bus and end user as shown below in Figure 1. Telemetry device is connected to vehicle CAN BUS and obtain CAN messages via its transreceiver. Obtained messages are evaluated with its Linux based processor according to SAE J1939-71 standard. Then telemetry device send CAN messages to big data infrastructure via $3 \mathrm{G}$ communication and driver information display via Ethernet. After gathering CAN messages on server, we can make big data analysis with designed web application. Also, we can define different user and authorization groups. Some of user groups have limited access and only can monitor allowed messages and design their own dashboards if needed, while some of groups have access to see all messages, making big data analysis and prepare reports for municipalities or customers about their vehicles and drivers. Allowed user groups also can work on error estimation and warn the driver and vehicle owner before the error occurs by analyzing all messages which are located on application database for a long time.

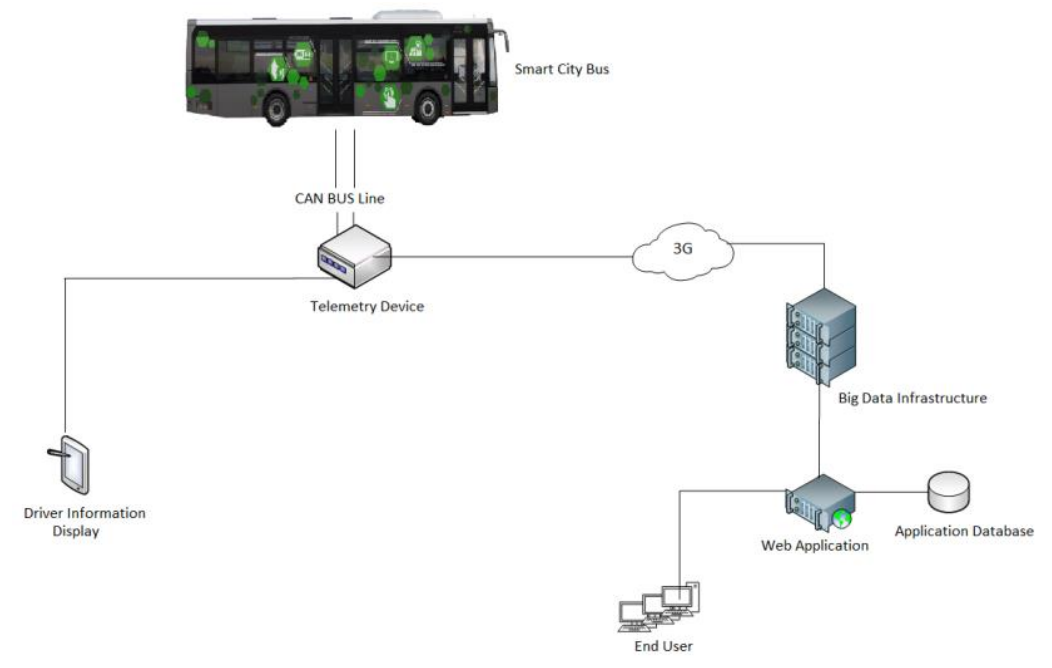

Fig.1 . General overview of the system 
Municipalities, owner or fleet manager can obtain location, engine speed, vehicle speed, throttle pedal position, brake pedal position, engine coolant level, engine coolant temperature, engine oil pressure, transmission oil pressure, engine oil level, fuel level, instantaneous/ average fuel consumption, total distance, trip distance, fuel consumption at idle speed, adblue level, adblue consumption, total engine working hour, total engine working hour at idle speed, average engine speed, average throttle pedal position, average vehicle speed, average fuel consumption, remaining $\mathrm{km}$ for maintenance, park brake status, brake lining thickness, door status, battery voltage, alternator status, front / rear brake tank pressure, current gear, retarder status, engine oil temperature, transmission oil temperature, compressor status, time date information, kick down status, failure status for engine, transmission, brake and suspension systems etc. These messages can be customized for customer demands. Some sample views of web application are shown below such as map view (Figure 2) and CAN BUS messages (Figure 3).

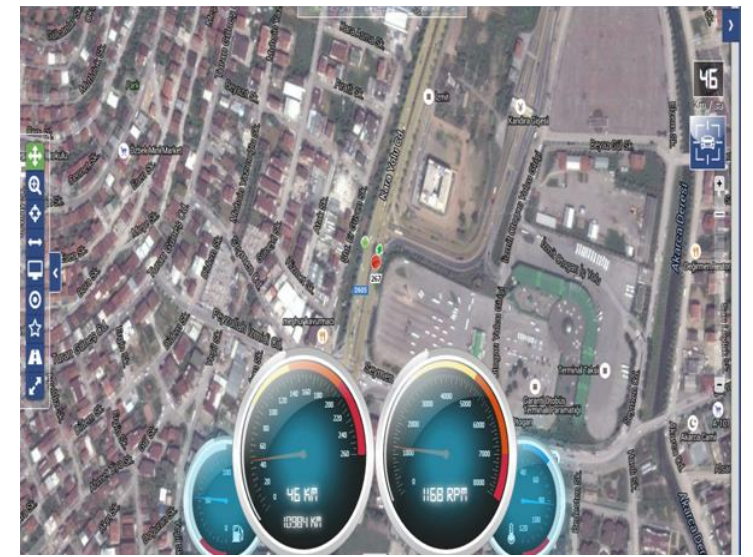

Fig. 2. A sample view from map view of the web application 


\begin{tabular}{|c|c|c|c|c|c|c|}
\hline $\begin{array}{l}\text { Time } \\
\text { Date }\end{array}$ & $\begin{array}{l}\text { Instantenous Rear Right } \\
\text { Fuel Cons. Brake Lining }\end{array}$ & $\begin{array}{l}\text { Throttle Pedal } \\
\text { Position }\end{array}$ & $\begin{array}{l}\text { Coolant } \\
\text { Temp. }\end{array}$ & $\begin{array}{l}\text { Vehicle } \\
\text { Speed }\end{array}$ & $\begin{array}{l}\text { Engine } \\
\text { Speed }\end{array}$ & $\begin{array}{l}\text { Total } \\
\text { Distance }\end{array}$ \\
\hline 016 06:14:05 & $1 \mathrm{~km} / \mathrm{t} 92 \%$ & $100 \%$ & $466^{\circ}$ & $49 \mathrm{~km} / \mathrm{sa}$ & 1690 PPM & $10330 \mathrm{~km}$ \\
\hline 2016 06:14:20 & $127 \mathrm{~km} / \mathrm{tt} 92 \%$ & 0\% & $47 c^{\circ}$ & $18 \mathrm{~km} / \mathrm{sa}$ & 1175 SPM & $10330 \mathrm{~km}$ \\
\hline ?016 06:14:34 & $1 \mathrm{~km} / \mathrm{t}$. & $100 \%$ & $48 c^{\circ}$ & $42 \mathrm{~km} / \mathrm{sa}$ & 1486 PPM & $10331 \mathrm{Km}$ \\
\hline 2016 06:14:48 & $1 \mathrm{~km} / \mathrm{tt}$ - & $77 \%$ & $490^{\circ}$ & $38 \mathrm{~km} / \mathrm{sa}$ & 1318 PPM & $10331 \mathrm{~km}$ \\
\hline :016 06:15:03 & $127 \mathrm{kmut}$ - & $0 \%$ & $51 \mathrm{C}^{\circ}$ & $42 \mathrm{~km} / \mathrm{sa}$ & 1480 PPM & $10331 \mathrm{~km}$ \\
\hline $201606: 15: 16$ & $1 \mathrm{Kmut} 92 \%$ & $100 \%$ & $516^{\circ}$ & $45 \mathrm{~km} / \mathrm{sa}$ & 1550 PPM & $10331 \mathrm{~km}$ \\
\hline $01606: 15: 31$ & $1 \mathrm{~km} / \mathrm{t} 92 \%$ & $100 \%$ & $53 \mathrm{C}^{\circ}$ & $65 \mathrm{~km} / \mathrm{sa}$ & 1630 PPM & $10331 \mathrm{~km}$ \\
\hline $01606: 15: 46$ & $1 \mathrm{~km} / \mathrm{t} 92 \%$ & $100 \%$ & $54 c^{\circ}$ & $71 \mathrm{~km} / \mathrm{sa}$ & 1820 PPM & $10331 \mathrm{~km}$ \\
\hline $201606: 16: 00$ & $2 \mathrm{~km} / \mathrm{t} 92 \%$ & $100 \%$ & $55 c^{\circ}$ & $81 \mathrm{~km} / \mathrm{sa}$ & $1735 \mathrm{PPM}$ & $10332 \mathrm{~km}$ \\
\hline$: 01606: 16: 14$ & $3 \mathrm{~km} / \mathrm{tt}$. & $100 \%$ & $570^{\circ}$ & $79 \mathrm{~km} / \mathrm{sa}$ & 1705 RPM & $10332 \mathrm{~km}$ \\
\hline$: 01606: 16: 29$ & $14 \mathrm{Km} / \mathrm{Lt} 92 \%$ & $100 \%$ & $570^{\circ}$ & $80 \mathrm{~km} / \mathrm{sa}$ & 1714 PPM & $10332 \mathrm{~km}$ \\
\hline $801606: 16: 43$ & $3 \mathrm{~km} / \mathrm{t}$ - & $100 \%$ & $58 C^{\circ}$ & $79 \mathrm{~km} / \mathrm{sa}$ & 1700 RPM & $10333 \mathrm{~km}$ \\
\hline $01606: 17: 00$ & $2 \mathrm{kmLt} 92 \%$ & $100 \%$ & $58 C^{\circ}$ & $78 \mathrm{~km} / \mathrm{sa}$ & 1675 PPM & $10333 \mathrm{~km}$ \\
\hline
\end{tabular}

\begin{tabular}{|c|c|c|c|c|c|c|}
\hline Time & Park Brake & Brake & Vehicle Front Right & Transmission & Engine & Engine \\
\hline & & & Speed Brake Lining & Oil lemp. & & 3. Oil Level \\
\hline 10.02.2016 06:11:00 & 0 & & $0 \mathrm{~km} / \mathrm{sa}$. & 4 & $82 \mathrm{~B}$ & $72 \%$ \\
\hline $10.02 .201606: 11: 14$ & 0 & & $0 \mathrm{~km} / \mathrm{sa} 94 \%$ & 44 & $82 \mathrm{~B}$ & $72 \%$ \\
\hline $10.02 .201606: 11: 29$ & 0 & & $0 \mathrm{Km} / \mathrm{sa} 94 \%$ & 45 & 748 & $72 \%$ \\
\hline $10.022 .201606: 11: 43$ & 0 & & $2 \mathrm{~km} / \mathrm{sa}$ - & 45 & 818 & $72 \%$ \\
\hline 10.02:2016 06:11:58 & - & & $1 \mathrm{~km} / \mathrm{sa}$. & 45 & 818 & $22 \%$ \\
\hline 10.02:2016 06:12:12 & - & & $6 \mathrm{~km} / \mathrm{ss}$ - & 46 & 928 & $72 \%$ \\
\hline 10.02:2016 06:12:26 & 0 & & $9 \mathrm{~km} / \mathrm{sa} 94 \%$ & to & 978 & $72 \%$ \\
\hline 10.02.2016 06:12:40 & 0 & & $18 \mathrm{~km} / \mathrm{sa} 94 \%$ & 46 & NB & $72 \%$ \\
\hline $10.02 .201606: 12: 54$ & - & & $9 \mathrm{~km} / 3 \mathrm{sa} 94 \%$ & 46 & 818 & $72 \%$ \\
\hline 10.02:2016 06:13:08 & 0 & 7 & $0 \mathrm{~km} / \mathrm{sa}$ - & 48 & 818 & $72 \%$ \\
\hline $10,02: 2016060: 13: 23$ & 0 & 0 & $0 \mathrm{~km} / \mathrm{sa}$. & 47 & 008 & 728 \\
\hline 10.02:2016 06:13:37 & 0 & 0 & $0 \mathrm{~km} / \mathrm{ss}$ - & 48 & 798 & $72 \%$ \\
\hline 10.02 .2016 os:13:51 & 0 & & $6 \mathrm{~km} / \mathrm{sa} 94 \%$ & 48 & 978 & $72 \%$ \\
\hline
\end{tabular}

Fig. 3. A sample view from CAN BUS messages of the web application

By this study, municipalities, owner or fleet manager can limit desired messages and the system warns them if the limited values are exceeded. For example, they can limit vehicle speed to $80 \mathrm{~km} / \mathrm{h}$ and if the driver exceeded this limit value, the system sends an e-mail and warns the responsible people. By processing gathered data, performance of drivers of the fleet can also be evaluated. Drivers can be rated according to their fuel consumption, engine speed, vehicle speed, current gear, throttle pedal position, brake pedal position etc. values.

With the application of this system, vehicle can be diagnosed without any need of special diagnose tool and all error codes for engine, transmission, brake, suspension and any other system in the bus can be monitored on fully programmable, touchable driver information display. Important messages can be monitored by drivers via touch- 
6 Enis AYTAR, Serkan MEZARCIÖZ, Murat DEMIRDÜZEN, Mert ÖZKAYNAK, Kadir AYDIN

able driver information display (Figure 4 and 5). Messages on touchable driver information display can be customized according to customer demands. If any error occurs with engine, transmission, brake or suspension system, corresponding text color returns to red and when the driver touches this text, related fault page screen opens automatically (Figure 6). The driver can realize the problem without any need of special diagnose tool. Also, if the driver exceeded limited values, corresponding value color returns to red to warn the driver.

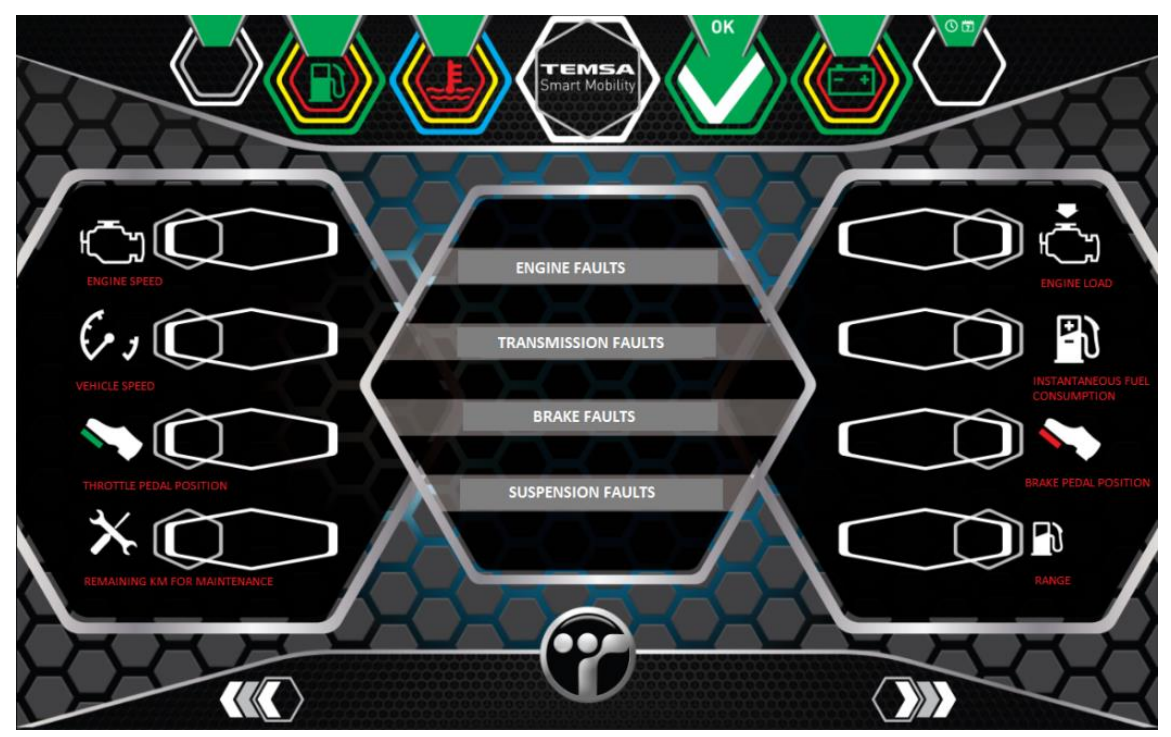

Fig. 4. Diagnose screen of the vehicle 


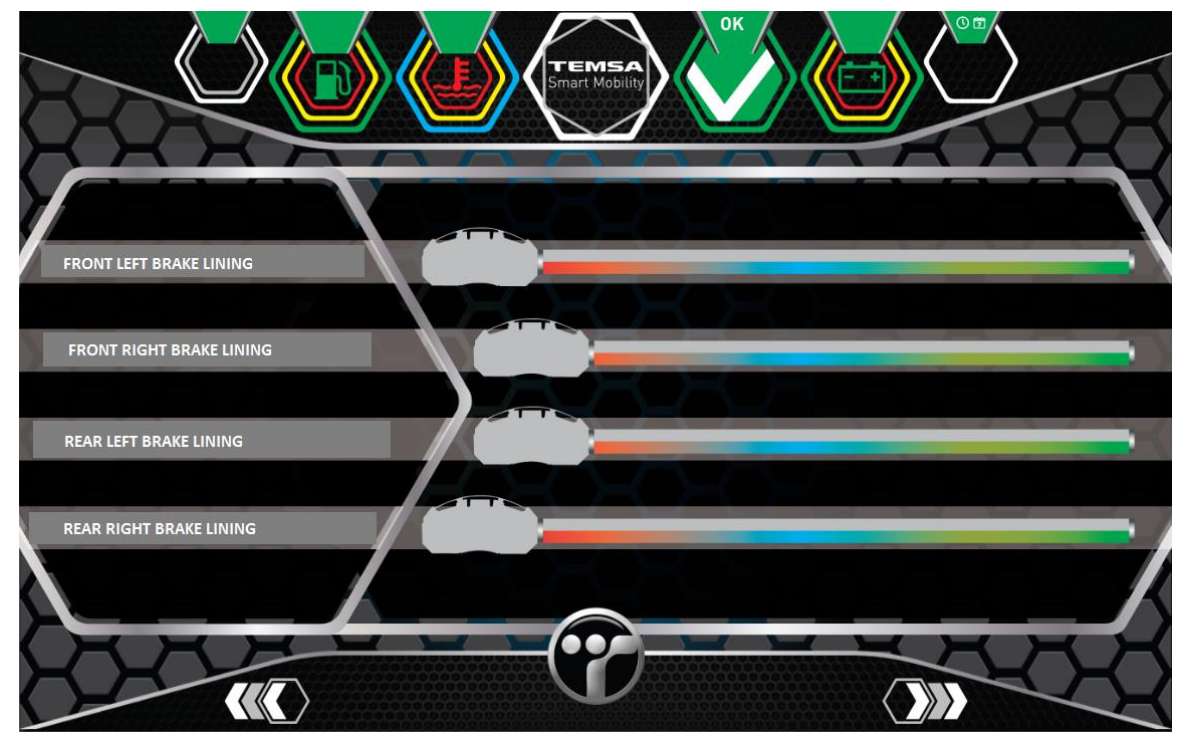

Fig. 5. Brake lining status of the vehicle

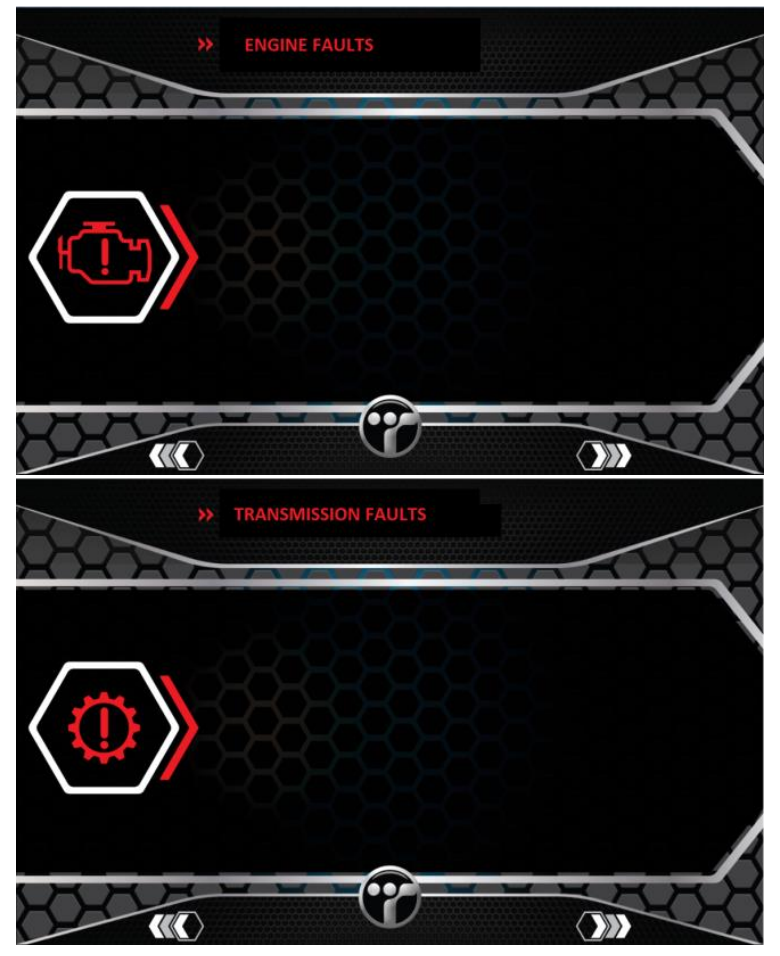

Fig. 6. A sample view from engine and transmission fault codes of the vehicle 
Another advantage of applying this system to the city bus is to see the condition of the vehicle, situation of the systems, error codes and special parameters like front / rear brake tank pressure, throttle pedal position, brake pedal position, park brake status just before any accident. These messages can help to find out the cause of the accident.

\section{CONCLUSSION}

According to (ENEA, 2016) experiences made so far in the EU countries, USA and Japan show that the introduction of ITS technologies has significantly contributed to improve the efficiency, safety, environmental impact and overall productivity of the transportation system. These applications, as pointed out by the European Commission, are an attractive solution to many of the problems of the transport sector: in the road sector it is possible to record reductions in journey times (15-20\%), in energy consumption $(12 \%)$ and in emissions of pollutants (10\%), as well as increases in network capacity $(5-10 \%)$ and decreases in the number of accidents (10-15 $\%)$. Significant results have also been achieved in the fleet management and logistics processes of goods and in the exercise of public passenger transport [3].

By this we expect to reduce maintenance cost and fuel consumption of vehicles by analyzing related messages which are located on application database. For example, if a customer complains about lifetime of brake linings, we analyze the vehicle messages and maybe we find out that the driver doesn't use retarder (auxiliary brake system for buses) and so lifetime of brake linings decrease. We inform the customer and driver about the relationship of retarder and brake linings to increase lifetime of brake linings. If a customer complains about fuel consumption, we analyze the vehicle messages and maybe we find out that the driver usually uses the vehicle at high engine speed, high throttle pedal percentage, unsuitable gear position and kick down situation or the driver starts the engine and wait for a long 
time at idle speed before starting its route. We give feedback to the customer and driver to reduce fuel consumption.

\section{REFERENCES}

[1]. Ezell, S.,2010, Intelligent Transportation Systems, The Information Technology \&Innovation Foundation, pp.58

[2]. Benevolo, C., Dameri, R. P., and D'Auria, B.,2016, Smart Mobility in Smart City Action Taxonomy, ICT Intensity and Public Benefits, Lecture Notes in Information Systems and Organisation, pp.17.

[3]. ENEA, http://old.enea.it/produzione_scientifica/pdf_brief/Valenti_ITStrasporti.pdf, 2016 